\title{
Use of single dose prophylactic magnesium sulphate in severe preeclampsia in preventing seizures
}

\author{
Shobha Bembalgi, Preet Kanwal* \\ Department of Obstetrics and Gynaecology, Karnataka Institute of Medical Sciences, Hubli, Karnataka, India
}

Received: 05 May 2016

Revised: 09 June 2016

Accepted: 10 June 2016

*Correspondence:

Dr. Preet Kanwal,

E-mail: preet.ldh12@gmail.com

Copyright: ( $\odot$ the author(s), publisher and licensee Medip Academy. This is an open-access article distributed under the terms of the Creative Commons Attribution Non-Commercial License, which permits unrestricted non-commercial use, distribution, and reproduction in any medium, provided the original work is properly cited.

\begin{abstract}
Background: Preeclampsia is a pregnancy specific multi organ disease process characterized by de novo development of hypertension and proteinuria after 20 weeks of gestation. Preeclampsia complicates 2-8\% of pregnancies.

Methods: We have studied 100 patients with severe preeclampsia who were randomly divided into two groups. One group received $4 \mathrm{gm}$ intravenous $\mathrm{MgSO}_{4}$ on admission which was prepared by diluting in $10 \mathrm{ml}$ normal saline and was given over 10-12 minutes slowly with strict monitoring. 50 patients of severe pre-eclampsia with B.P $>160 / 110$ $\mathrm{mm}$ of $\mathrm{Hg}$ were given the prophylactic dose and rest 50 acted as controls. Monitoring of B.P., urine output; respiratory rate and FHS was done.

Results: We have 1 case of seizure after 8 hours of giving loading dose, which was changed to Pritchard's regimen for further management whereas 7 patients had in the control groups. There were no cases of magnesium toxicity seen. There were no cases of maternal deaths and postpartum convulsions.

Conclusions: Single loading dose of magnesium sulphate is an efficient prophylactic in preventing eclampsia.
\end{abstract}

Keywords: Preeclampsia, Pregnancies, Monitoring

\section{INTRODUCTION}

Hypertensive disorders complicate 5 to 10 percent of all pregnancies, and together they are one member of the deadly triad along with haemorrhage and infection that contributes greatly to maternal morbidity and mortality. Of these disorders, the preeclampsia syndrome, either alone or superimposed on chronic hypertension, is the most dangerous. ${ }^{1}$ The WHO systematically reviews maternal mortality worldwide, and in developed countries, 16 percent of maternal deaths were reported to be due to hypertensive disorders Khan. ${ }^{2}$ Hypertensive disorders are responsible for not only maternal deaths but also substantial morbidity for pregnant women, they also carry risk for baby. Preeclampsia is the leading single identifiable risk factor associated with stillbirth.
Magnesium sulphate is used as first line anticonvulsant in pregnancy. ${ }^{3}$ Pritchard introduced the regimen for this drug in patients with eclampsia. ${ }^{4}$ The placebo-controlled study that enrolled over 10,000 women in 33 countries Magpie trial established the effectiveness of $\mathrm{MgSO}_{4}$ in the treatment of severe preeclampsia and eclampsia. ${ }^{5}$ There was significant reduction in convulsion rates when compared with diazepam and phenytoin along with improved outcomes for new-borns compared to phenytoin. Furthermore with a randomised controlled trial showing that seizures can be effectively controlled in cases of eclampsia by giving only the loading dose, it can be hypothesised that there is role of less doses of magnesium sulphate than the existing regimes in the prevention of seizures in patients of severe preeclampsia. 6,7 


\section{METHODS}

The study included 100 antepartum patients who met the criteria of severe preeclampsia (ACOG 2013b) admitted in labour room. ${ }^{8}$ It was conducted from November 2015 to January 2016 at Karnataka institute of medical sciences, Hubballi, Karnataka, India. The patients were randomly divided into two groups each having 50 females. One group received $4 \mathrm{gm}$ intravenous $\mathrm{MgSO}_{4}$ on admission which was prepared by diluting in $10 \mathrm{ml}$ normal saline and was given over 10-12 minutes slowly with strict vitals monitoring. 50 patients of severe preeclampsia with $\mathrm{BP}>160 / 110 \mathrm{~mm}$ of $\mathrm{Hg}$ were given the prophylactic dose and rest 50 acted as controls. Strict monitoring of BP, urine output; respiratory rate and FHS was done. Detailed history, clinical examination and investigations (complete blood count, urine analysis for proteinuria, liver and renal function tests, serum LDH, coagulation profile, evidence of hemolysis in peripheral blood smear, obstetric ultrasound with colour doppler).

Daily BP, urine output, urine albumin and FHS record were strictly monitored from admission up to 2 days after she delivered. Patients with chronic hypertension and those with pre-existing renal compromise were excluded from the study.

\section{RESULTS}

It was observed that most of the patients were primigravidas (46\% in cases and $56 \%$ in controls) (Table 2). The mean age of the patients was respectively 23.9 years and 23.29 years (Table 1 ).

Table 1: Age distribution.

\begin{tabular}{|lll|}
\hline Age & $\begin{array}{l}\text { Received } \\
\mathrm{MgSO}_{4}\end{array}$ & $\begin{array}{l}\text { Did not receive } \\
\mathrm{MgSO}_{4}\end{array}$ \\
\hline$<20$ years & 13 & 12 \\
\hline 20-25 years & 23 & 23 \\
\hline 26-30 years & 11 & 10 \\
\hline$>30$ years & 3 & 5 \\
\hline Mean & 23.9 & 23.26 \\
\hline
\end{tabular}

Table 2: Parity of the patients.

\begin{tabular}{|lll|}
\hline Parity & $\begin{array}{l}\text { Received } \\
\mathrm{MgSO}_{4}\end{array}$ & $\begin{array}{l}\text { Did not receive } \\
\mathrm{MgSO}_{4}\end{array}$ \\
\hline Primi & 23 & 28 \\
\hline Gravida 2 & 12 & 11 \\
\hline Gravida 3 & 11 & 07 \\
\hline Gravida 4 & 3 & 04 \\
\hline Gravida 5 and above & 1 & 00 \\
\hline
\end{tabular}

In regard to their gestation age, the majority were of term gestation with mean gestation age between 38-39 weeks in both the groups (Table 3). Majority of them had vaginal delivery where 14 and 16 patients respectively were induced. The rate of LSCS was $32 \%$ and $30 \%$ respectively in cases and controls (Figure 1).
Table 3: Mean gestational age.

\begin{tabular}{|ll|l|}
\hline Gestational age & $\begin{array}{l}\text { Received } \\
\mathrm{MgSO}_{4}\end{array}$ & $\begin{array}{l}\text { Did not receive } \\
\mathrm{MgSO}_{4}\end{array}$ \\
\hline$<28$ weeks & 0 & 1 \\
\hline 28 to 34 weeks & 5 & 1 \\
\hline 34 to 37 weeks & 7 & 12 \\
\hline 37 to 40 weeks & 28 & 23 \\
\hline 40 to 42 weeks & 10 & 13 \\
\hline Mean & 38 weeks 1 day & 38 weeks 4 days \\
\hline
\end{tabular}

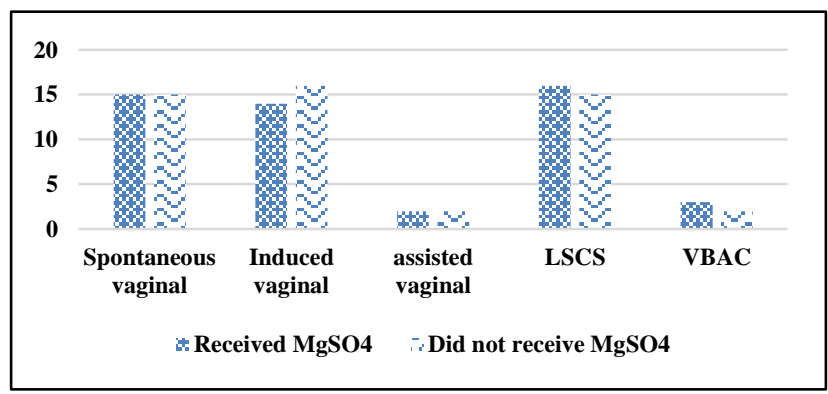

Figure: 1 Mode of delivery.

There were 3 cases of atonic PPH in those who received injection $\mathrm{MgSO}_{4}$ whereas 2 cases were observed in those who didn't. Out of 50 patients who received prophylactic dose only 1 had convulsions whereas 7 patients had convulsions in the group who didn't receive. There was no incidence of postpartum convulsions or maternal mortality in both the groups.

8 babies were admitted in NICU who had received injection magnesium sulphate whereas 13 babies had NICU admission in those who didn't receive the injection.

Table 4: Complications.

\begin{tabular}{|llll|}
\hline & $\begin{array}{l}\text { Received } \\
\mathrm{MgSO}_{4}\end{array}$ & $\begin{array}{l}\text { Did not receive } \\
\mathrm{MgSO}_{4}\end{array}$ & p value \\
\hline Convulsions & 1 & 7 & 0.027 \\
\hline Atonic $\mathrm{PPH}$ & 3 & 2 & 0.650 \\
\hline Mortality & 0 & 0 & \\
\hline
\end{tabular}

Table 5: Neonatal outcome.

\begin{tabular}{|lll|}
\hline & $\begin{array}{l}\text { Received } \\
\mathrm{MgSO}_{4}\end{array}$ & $\begin{array}{l}\text { Did not receive } \\
\mathrm{MgSO}_{4}\end{array}$ \\
\hline NICU admissions & 08 & 13 \\
\hline FSB & 02 & 04 \\
\hline
\end{tabular}

\section{DISCUSSION}

Magnesium sulphate is the drugs of choice for seizure prophylaxis in patients of severe pre-eclampsia. ${ }^{5}$ World over different regimes are being used. Our study consisted of using lowest dose of magnesium sulphate to have maximum benefits with least toxicity. The primary objective of our study was to prevent or reduce the rate of 
eclampsia with least toxicity. The secondary benefit of this drug was to reduce maternal and perinatal mortality and morbidity.

There are different studies following different regimens for the administration of injection magnesium sulphate. Various trials have adopted different routes, dosages and time to start therapy. Among the trials using intra-venous regime, the loading dose ranged from 4-6 gm and the maintenance dose ranged from 1-2 g/hour Coetzee et al, Belfort et al, Shah R and Mehandale SS. ${ }^{9-12}$

In our study we gave 50 patients with BP>160/100, 4 gm single dose intravenous $\mathrm{MgSo}_{4}$ on admission which was prepared by diluting in $10 \mathrm{ml}$ normal saline and was given over 10-12 minutes slowly.

In the magpie trial the incidence of seizures in patients of severe preeclampsia including those with impending eclampsia $(n=2174)$ receiving the placebo was $3.12 \%{ }^{5}$ This risk was reduced to $1.09 \%$ in patients of severe preeclampsia including those with impending eclampsia $(n=2107)$ who were given magnesium sulphate. The trial concluded that there was a reduction of $58 \%$ in the risk of occurrence of seizures regardless of the severity of the disease by using magnesium sulphate. The trial by Coetzee et al included 822 randomized women, there were no cases of eclampsia seen when magnesium sulphate prophylaxis was used in severe preeclampsia cases. $^{9}$

In a similar study comparing single dose versus modified Pritchard regimen they observed that rate of convulsions was equal in both the groups with minimum adverse effects with low dose. ${ }^{10}$ A study conducted by Shah and Mehendale concluded that single loading dose of magnesium sulphate in severe pre-eclampsia is effective in preventing eclampsia in $97 \%$ cases. $^{11}$

In present study, we have 1 case of seizure after 8 hours of giving loading dose, which was changed to Pritchards regimen for further management whereas 7 patients had in the control groups. There were no cases of magnesium toxicity seen. There were no cases of maternal deaths and postpartum convulsions.

The limitation of this study was sample size was small so further studies are warranted to know the efficacy of the drug.

\section{CONCLUSION}

A single dose magnesium sulphate can be used prophylactically in cases of severe preeclampsia to reduce the incidence of seizures especially in a resource poor country like ours. With minimal monitoring required this can be adopted in peripheral centres which can help to reduce maternal mortality and morbidity and improve perinatal outcome.
Funding: No funding sources

Conflict of interest: None declared

Ethical approval: The study was approved by the Institutional Ethics Committee

\section{REFERENCES}

1. Cunningham FG, Leveno KJ, Bloom SL, Spong CY, Dashe JS, Hoffman BL, et al. Williams Obstetrics $24^{\text {th }}$ edition, McGraw-Hill Companies, Inc; 2014.

2. Khan KS, Wojdyla D, Say L, Gülmezoglu AM, Van Look PF. WHO analysis of causes of maternal death: a systematic review. Lancet. 2006;367:1066.

3. The eclampsia trial collaborative group. Which anticonvulsant for women with eclampsia? Evidence from the collaborative eclampsia trial. Lancet. 1995;345:1455-63.

4. Pritchard JA. The use of magnesium ion in the management of eclamptogenictoxemias. Surg Gynecol Obstet. 1955;100(2):131-40.

5. The magpie trial collaborative group. Do women with pre-eclampsia, and their babies, benefit from magnesium sulphate? The magpie trial: a randomised placebo- controlled trial. Lancet. 2002;359:1877-90.

6. Begum MR, Begum A, Quadir E. Loading dose versus standard regime of magnesium sulphate in the management of eclampsia: a randomized trial. Obstet Gynaecol. 2002;28:154-9.

7. Suman S, Shinanjalin M, Ajit P, Uday P. Low dose magnesium sulphate therapy for eclampsia and imminent eclampsia: regimen tailored for Indian women. J Obstet Gynecol Indi. 2003;55:546-50.

8. Hypertension in pregnancy. American college of Obstetrics and Gynaecology (2013b) Criteria for severe preeclampsia; 2013.

9. Coetzee EJ, Dommisse J, Anthony J. A randomized controlled trial of intravenous magnesium sulphate versus placebo in the management of women with severe pre-eclampsia. An International Journal of Obstetrics and Gynaecology. 1998;105(3):300-3.

10. Ranganna H, Saha SC, Thami MR, Kumar P. Prophylactic magnesium sulphate in severe preeclampsia- loading dose only versus conventional 24 hours therapy of modified Pritchard's regime: a randomized trial. IOSR Journal Of Pharmacy. 2014;4(6):39-47.

11. Shah R, Mehendale SS. 4 gm intravenous magnesium sulphate in severe preeclampsia for prevention of eclamspia. Indian Journal of Applied Research. 2014;4(3):422-3.

12. Belfort MA, Anthony J, Saade GR, Allen JC. A comparison of magnesium sulfate and nimodipine for the prevention of eclampsia. $\mathrm{N}$ Eng $\mathrm{J}$ Med. 2003;348:304-11.

Cite this article as: Bembalgi S, Kanwal P. Use of single dose prophylactic magnesium sulphate in severe preeclampsia in preventing seizures. Int $\mathbf{J}$ Reprod Contracept Obstet Gynecol 2016;5:2261-3. 